\title{
A Study on Theory of Body in Maurice Merleau-Ponty's Phenomenology - From the viewpoint of 'Waza' in Japanese High School Baseball -
}

\author{
Shuhei KITAGAWA ${ }^{*}$, Kentaro TAI ${ }^{2}$, \& Kohki KINIWA ${ }^{3}$ \\ ${ }^{1}$ Hiroshima University Graduate School of Integrated Arts and Sciences (Japan) \\ ${ }^{2}$ Nagasaki International University (Japan) \\ ${ }^{3}$ Hiroshima University Graduate School of Integrated Arts and Sciences (Japan)
}

\section{5th IMACSSS World Scientific Congress Abstracts, Rio Maior (Portugal), October 6-8 Section: Historical, sociological and philosophical issues of MA\&CS Type: Poster communication}

\section{Introduction}

This study aims to expand the theory of body in Maurice Merleau-Ponty's phenomenology from the viewpoint of 'Waza' (skill or craft) that is a global skill of mind and body in Japanese high school baseball. Japanese high school baseball has mainly been developing in relation with Budo (Japanese martial arts) and Japanese school education system that take a role of the cultivation of mind and body. Japanese high school baseball is still regarded as Budo by many Japanese funs and is sometimes called 'Yakyudo' for Budo. 'Waza' is an important concept in Budo. It is the same also in Japanese high school baseball. 'Waza' is not simply technique and physical or intellectual ability. The authors assume that 'Waza' includes a style of the life world (Lebenswelt) to which people should commit themselves in the acquisition of 'Waza'.

\section{Methodology}

There are three stages of 'Shu-Ha-Ri' in order to acquire 'Waza' in Budo. 'Shu' (preservation) is for disciple to imitate the action of the master. 'Ha' (breaking) is for disciple to reflect on the action of the master, to think about the action of other schools and to develop the action of the master. 'Ri' (detaching) is for disciple to add his originality to the action and to create an original new action. In this study the authors try to explain these processes on the basis of theory of body in Maurice Merleau-Ponty's phenomenology. Since he considered the Japanese mien and gesture as well as action of sports, the authors assume that his phenomenological theory of body has the methodological validity of the consideration of Budo and Japanese high school baseball.

\section{Results}

'Shu' is for disciple to imitate and preserve the action of his master. Merleau-Ponty mentioned that imitation is for me to project myself on other and assimilate myself with other. In Japanese high school baseball this assimilation is almost compulsorily practiced in accordance with the Japanese habit of hierarchy system based on edge (loyalty to coach, teacher and senior student etc.). The most of new students are forced to be shaved heads and to learn the manner of greeting, cleaning, and maintenance of sporting goods etc. from their coach and senior students. The new students and junior students project themselves on the senior students and assimilate themselves with the senior students, through acquiring both the form of baseball technique and the manner of the action that the senior students act in their life world.

'Ha' is for disciple to reflect on the action of his master and to develop the traditional action. It is the same also for high school baseball players to reflect on their life world and to develop the manner 
of their action. That is a reflection about the non-reflective or pre-linguistic events on the basis of the concept of perception and experience in Maurice Merleau-Ponty. They grasp intercorporeally the habitual action of their coach and the other high school baseball players, at the same time that they repress the action unsuitable for Japanese high school baseball player (e.g. protesting to the referee, the base stealing on the condition of having a decisive win in a game etc.). But on the other hand they are leading to break and improve their traditional form and manner (e.g. the rapid tempo in transition of batting and fielding, the manner of wearing their uniforms, etc.).

'Ri' is to create an original new action suitable for the intercorporeality and the life world through the above mentioned imitation and reflection. Maurice Merleau-Ponty mentioned the concept of 'transgression intentionnelle' that we try to gaze other and at the same time we are gazed by other. He also mentioned that it just enables for us to touch or be touched (detach from) the existence of other and discover the truth in the life world. That is the meaning that other admits our free action as universal one when we discover other in their gestures and a scene of the life world of high school baseball (e.g. Koshien stadium as a holy place). 'Waza' assimilates itself with the events and at the same time it is also given a new meaning when Japanese high school baseball players dedicate themselves to their 'Ma' (an appropriate moment and place to each situation) and they are praised by events which they act.

\section{Discussion and conclusion}

As the results of the phenomenological considering 'Waza', the authors clarified that it was impossible to explain about the embodiment of Japanese high school baseball without the relation with life world and other (coach, teacher, senior student and parents etc.), since high school baseball players have traditionally repeated 'Shu-Ha-Ri' and acquired 'Waza' that is the global skill of mind and body. 'Waza' assimilates itself with the events and at the same time it is also given a new meaning when Japanese high school baseball players dedicate themselves to their ' $\mathrm{Ma}$ ' (an appropriate moment and place to each situation). It seems that 'Shu-Ha-Ri'might be discovered in the process of acquiring and creating the technique of the other sports. We should consider the embodiment of sports from the viewpoint of not only biomechanics and physiology but also 'Waza'. The future topic is to clarify the embodiment of other sports and dance on the basis of the embodiment of 'Waza'.

\section{References}

Merleau-Ponty, M. (1976). Phenomenologie de la perception. Paris: Gallimard. Ikuta, K. (2007).Waza kara shiru[ Perceive from Waza]. Tokyo: University of Tokyo Press.

Key words: Budo; martial arts; waza; shu-ha-ri; life world; intercorporeality; ma. 